\title{
Coronary angioplasty for in-stent restenosis in patient with anomalous single coronary artery arising from right sinus valsalva
}

\author{
Göksel Açar, Serdar Fidan*, Servet İzci, Elnur Alizade
}

Kartal Koşuyolu Heart Education and Research Hospital, Cardiology Clinic, Istanbul, Turkey

Email: dr_serdar86@hotmail.com

Received 9 April 2013; revised 9 May 2013; accepted 16 May 2013

Copyright (C) 2013 Göksel Açar et al. This is an open access article distributed under the Creative Commons Attribution License, which permits unrestricted use, distribution, and reproduction in any medium, provided the original work is properly cited.

\begin{abstract}
Single coronary artery is a coincidental finding during coronary angiography or at autopsy. Although it is a rare condition and most of time has an asymptomatic clinic; prognosis varies. We would like to report a case about percutaneous coronary intervention in a patient who has anomalous single coronary artery arising from right sinus valsalva.
\end{abstract}

Keywords: Coronary Anomaly; Single Coronary Artery; Percutaneous Coronary Intervention

\section{INTRODUCTION}

Single coronary artery (SCA) is a rare congenital anomaly defined as an isolated coronary artery, which originates from the aortic root through a single ostium and does not include evidence of a second ostium. Therefore, it provides blood needed to the whole heart, regardless of its distribution. Although it is a rare condition and most of time has an asymptomatic clinic; prognosis varies. We would like to report a case about percutaneous coronary intervention (PCI) in a patient who has anomalous single coronary artery arising from right sinus valsalva.

\section{CASE REPORT}

A 62-year-old male patient with a history of hypertension, hypercholesterolemia and smoking was admitted to our emergency department because of substernal chest pain for 2 days. Additionally, an acute inferoseptal myocardial infarction was included in his medical history with complete resolution after a bare metal stent deployment 1 year ago and he was on medication with acetylsalicylic

\footnotetext{
"Corresponding author.
}

acid, clopidogrel, metoprolol, valsartan and atorvastatin because of that. On his admission electrocardiogram (ECG) showed sinus rhythm with heart rate of 60 beat per minute and loss of " $R$ " progression in V1-V3. No remarkable findings were noticed on his physical examination. His chest X-ray was normal. However, regional wall motion abnormality of inferior and inferior septum segments with an ejection fraction of $50 \%$ were observed in his transthoracic echocardiogram. Cardiac markers were above normal limits. The patient got pain free after perlinganit infusion. We evaluated him as non ST elevation myocardial infarction and decided for coronary angiography. The patient underwent coronary angiography, which revealed an anomalous single coronary artery originated from right coronary sinus, together with the absence of right coronary artery. Furthermore, the right coronary artery and the left anterior descending artery appeared to continue without significant stenotic lesions. There was a significant stenotic lesion in distal margin of the previously implanted stent in left circumflex artery, which was the probable cause of the clinical picture (Figure 1). Transluminal coronary angioplasty with coronary stent implantation was chosen. In this procedure, femoral approach was carried out using a right Judkins 4 (JR 4) $7 \mathrm{~F}$ guiding catheter as in his previous myocardial infarction and single coronary artery was cannulated with a JR4 catheter. While selection of the single coronary artery, the 0.014 inch guidewire promoted toward the left circumflex artery. After adequate positioning of the guidewire in the distal part of the left circumflex artery and lesion predilated with a $2.0 \times 20 \mathrm{~mm}$ balloon, then a 2.5 $\times 20 \mathrm{~mm}$ stent was implanted with primary success and TIMI III distal coronary flow (Figure 2). The patient had an uneventful recovery and was discharged on medical therapy with aspirin, clopidogrel, beta blocker, angiotensin-converting enzyme inhibitor and statin 3 days later. 


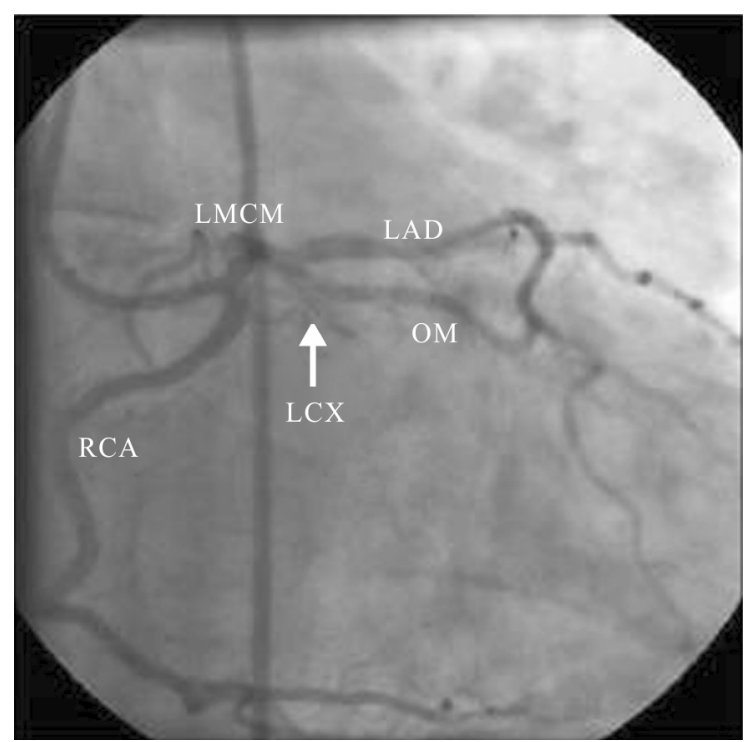

Figure 1. Coronary angiography showing an anomalous single coronary artery originating from the right sinus of valsalva. The anomalous vessel branches into RCA, which has normal course, and a short LMCA. This vessel then branches into LAD and LCX. Critical lesion in the midportion of the LCX (arrow).

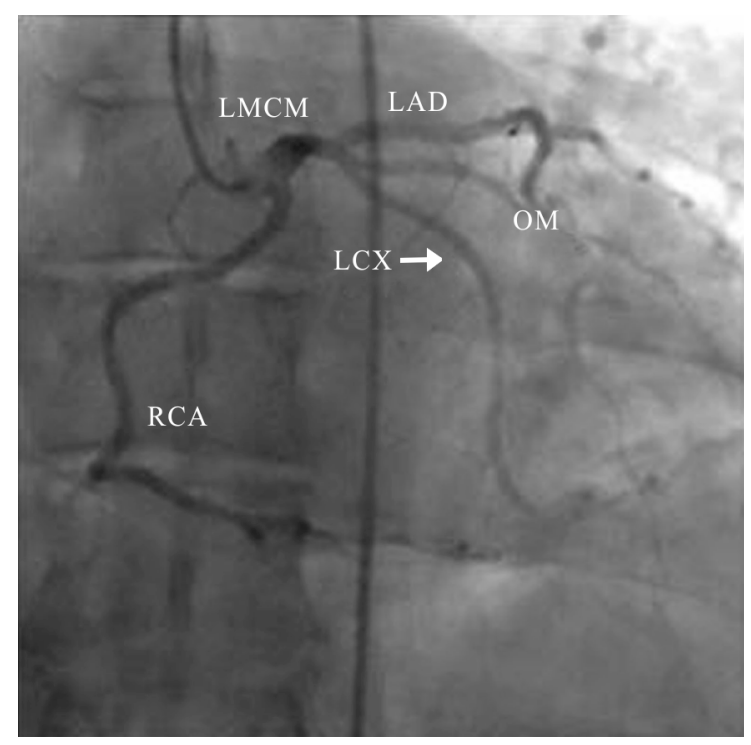

Figure 2. Coronary angiography after stent deployment.

\section{DISCUSSION}

The incidence of all coronary anomalies is $0.23 \%$ in necropsy series and ranges between $0.3 \%$ and $12 \%$ in angiographic series [1]. Various classification systems exist for coronary artery anomalies in terms of their anatomic characteristics such as origin and course [2]. Kim et al. divided coronary anomalies anatomic characteristics, i.e., anomalies of origin, anomalies of course, and anomalies of termination [3]. So, single coronary artery is a kind of anomalies of origin in this classification. Single coronary artery is a rare congenital anomaly in which only one coronary artery arises from the aortic sinus and the blood supply of the whole heart is provided by it. This type of anomaly occurs in only $0.0024 \%-0.044 \%$ of the population [4]. They are usually encountered as coincidental findings during coronary angiography or at autopsy. Most of the patients with a single coronary artery have a normal life-expectancy and asymptomatic. Although those patients are usually asymptomatic, they may develop syncope, angina pectoris, MI, ventricular arrhythmias and sudden death, especially during or after exercise [5-7]. In the case of major coronary arterial branches running between the aorta and the pulmonary arteries; the risk of complications increases. Proximal stenosis of a single coronary can result in a worse outcome than that in normal patients. There are a few reports written about PCI in patients with coronary artery anomalies even less in acute coronary syndrome $[8,9]$ as our case. Dissection of the ostium and occlusion of the single main stem can be very risky, even fatal. As a result, cannulation of single coronary artery is very difficult and dangerous in some cases. In the success of PTCA in anomalous arteries, catheter support plays a very significant role. To the best of our knowledge, there has not been any written case which has undergone PCI for in-stent restenosis which caused acute coronary syndrome clinic in a patient with SCA up to now.

\section{CONCLUSION}

Single coronary artery may be an asymptomatic congenital alteration detected in patients with myocardial ischemia due to atherosclerotic coronary artery disease. In these cases percutaneous coronary angioplasty with stent implantation may be a successful therapeutic option; however, accurate morphologic identification of anomalous arteries is mandatory before planning these interventions. In order to recognize other possible mechanisms of myocardial ischemia (e.g. vascular compression) and to choose the most appropriate type of pharmacological, percutaneous or surgical intervention, other imaging techniques, like coronary computed tomography or magnetic resonance imaging, may be useful in order to correctly identify the origin and course of abnormal coronary arteries.

\section{REFERENCES}

[1] Vilallonga, J.R. (2004) Anatomical variations in the coronary arteries. II. Less prevalent variations: Coronary anomalies. European Journal of Anatomy, 8, 39-53.

[2] Angelini, P., Velasco, J.A. and Flamm, S. (2002) Coronary anomalies incidence, pathophysiology, and clinical relevance. Circulation, 105, 2449-2454. 


\section{doi:10.1161/01.CIR.0000016175.49835.57}

[3] Kim, S.Y., Seo, J.B., Do, K.H., Heo, J.N., Lee, J.S., Song, J.W., et al. (2006) Coronary artery anomalies: Classification and ECG-gated multi-detector row CT findings with angiographic correlation. Radiographics, 26, 317-334. doi:10.1148/rg.262055068

[4] Desmet, W., Vanhaecke, J., Vrolix, M., Van de Werf, F., Piessens, J., Willems, J., et al. (1992) Isolated single coronary artery: A review of 50,000 consecutive coronary artery angiographies. European Heart Journal, 13, 16371640.

[5] Yokoyama, H.A., Pessoa, C.M., Carvalho, F.C., Campos, R.F., Franco, R.J. and Bregagnollo, E.A. (2007) Percutaneos coronary intervention in single coronary artery in a patient with high-risk unstable angina. Arquivos Brasileiros de Cardiologia, 88, 51-53.

[6] Chaitman, B.R., Lesperance, J., Saltiel, J. and Bourassa, M.G. (1976) Clinical, angiographic, and hemodynamic findings in patients with anomalous orgin of the coronary arteries. Circulation, 53, 122-131. doi:10.1161/01.CIR.53.1.122

[7] Yamanka, O. and Hobbs, R.E. (1990) Coronary ertery anomalies in 126,595 patients undergoing coronary arteriography. Catheterization and Cardiovascular Diagnosis, 21, 28-40. doi: $10.1002 / \mathrm{ccd} .1810210110$

[8] Baljepally, R.M., Pollock, S.H. and Magram, M.Y. (1993) Transluminal angioplasty of a single coronary artery anomaly during acute myocardial infarction: A case report. Angiology, 44, 981-984. doi: $10.1177 / 000331979304401210$

[9] Ohta, H., Sumiyoshi, M., Suwa, S., Tamura, H., Sasaki, A., Kojima, T., et al. (2003) Primary coronary angioplasty with stenting for acute coronary syndrome in patients with isolated single coronary artery. A report of two cases. Japanese Heart Journal, 44, 759-765. doi:10.1536/jhj.44.759 